\title{
JUVENTUDE E EDUCAÇÃO NO CONTEXTO DO DESEMPREGO CRÔNICO NA ESPANHA E NO BRASIL
}

\author{
YOUTH AND EDUCATION IN THE CONTEXT OF CHRONIC \\ UNEMPLOYMENT IN SPAIN AND BRAZIL
}

\section{LA JUVENTUD E LA EDUCACIÓN EN EL CONTEXTO DEL DESEMPLEO CRÓNICO EN ESPAÑA Y EN BRASIL}

DOI: http://dx.doi.org/10.9771/gmed.v11i1.31474

\author{
Mauro Titton ${ }^{1}$ \\ Adriana D'Agostini ${ }^{2}$
}

Resumo: O artigo aborda a juventude no contexto do desemprego crônico na Espanha e no Brasil. Busca demonstrar como o desenvolvimento da crise estrutural do sistema capitalista e suas estratégias, como a criação dos organismos internacionais, os ajustes estruturais e a destruição das forças produtivas através das expropriações e da exploração ampliam o desemprego crônico, ao invés de reduzi-lo, como anunciado. Para a juventude, a Espanha tenta contornar a situação prioritariamente por duas políticas públicas: LOMCE e Garantía Juvenil; o Brasil segue a mesma lógica destas políticas, através da reforma do Ensino Médio e o programa Projovem, por exemplo. Apesar das estratégias comuns e dos investimentos elevados, a situação persiste e as políticas focais em voga não são suficientes sequer para amenizar a situação. Nesse contexto estreitam-se as possibilidades para a juventude projetar seu futuro.

Palavras-chave: Desemprego. Crise Estrutural. Juventude.

Abstract: The article broaches youth in the context of chronic unemployment in Spain and Brazil. It demonstrates how the development of the structural crisis of the capitalist system and its strategies, such as the creation of international organizations, structural adjustments, and the destruction of the productive forces through expropriation and exploitation, expand chronic unemployment rather than reduce it as announced. To youth, Spain tries to circumvent the situation primarily by two public policies: LOMCE and Juvenile Guarantee; Brazil follows the same logic of these policies, through the High School reform and Projovem program, for example. Despite the common strategies and high investments, the situation persists and the focal policies in vogue are not enough to assuage the situation. In this context, the possibilities to youth project their future are narrowed.

Keywords: Unemployment. Structural Crisis. Youth.

Resumen: El artículo enfoca la juventud en el contexto del desempleo crónico en España y Brasil. Demuestra cómo el desarrollo de la crisis estructural del sistema capitalista y sus estrategias, como la creación de los organismos internacionales, los ajustes estructurales y la destrucción de las fuerzas productivas a través de las expropiaciones y la explotación, amplían el desempleo crónico, en lugar de reducirlo, como anunciado. Para la juventud, España intenta resolver la situación prioritariamente por medio de dos políticas: la LOMCE y el Garantía Juvenil; Brasil sigue la misma lógica de estas políticas, a través de la reforma de la Enseñanza de Nivel Medio y el programa Projovem, por ejemplo. A pesar de las estrategias comunes y de las inversiones elevadas, la situación persiste y las políticas focales en boga no bastan para suavizar la situación. En ese contexto se estrechan las posibilidades para que la juventud proyecte su futuro. Palabras-clave: Desempleo. Crisis Estructural. Juventud.

\section{Introdução}


Diversos estudos (LEÃO E NONATO, 2012; SILVA, QUARTIERO e EVANGELISTA, 2012; ZUCK, 2014; SILVA, 2015; CONDE, MARCASSA, TITTON e VENDRAMINI, 2017) tem evidenciado que as desigualdades sociais têm uma relevância central nas trajetórias de vida dos jovens, ao condicionarem as suas experiências atuais impactando suas expectativas em relação ao futuro.

Mesmo com o propalado crescimento econômico em diversos países e regiões do mundo, a persistência da miséria e o aumento das desigualdades impactam a vida das populações, em especial da juventude. Entretanto, mais do que um elemento conjuntural, a persistência e aumento das desigualdades sociais são próprios do desenvolvimento do sistema do capital em sua fase atual, com seu contínuo e crescente processo de expropriações (FONTES, 2010). A compreensão da crise do sistema do capital, fruto de sua forma expansiva e incontrolável em escala mundial (MÉSZÁROS, 2002), é componente essencial para apreender as relações sociais reais nas quais a juventude produz sua existência na atualidade, segundo as possibilidades nelas presentes.

Compreendemos que a atual crise do sistema se constitui em uma crise estrutural, que para garantir o processo de expansão do capital mantém constantemente crises de diferentes intensidades e duração, mantendo assim seu dinamismo operacional e seus meios de dominação. Segundo Mészáros (2002, p. 796), a crise atual do sistema é estrutural por seu caráter universal, seu alcance global, sua escala de tempo contínua ou permanente e seu modo rastejante de desdobrar-se - isto é, em contraste com as erupções e colapsos mais espetaculares e dramáticos do passado, a crise atual persiste e utiliza-se de elementos de "administração da crise" e "deslocamento" das contradições. Ainda, uma crise é estrutural quando "afeta a totalidade de um complexo social em todas as relações com suas partes constituintes ou subcomplexos, como também a outros complexos aos quais é articulada" (Ibidem, p. 797). Assim, a atual crise é diversa da crise não estrutural que "afeta apenas algumas partes do complexo em questão, e assim, não importa o grau de severidade em relação às partes afetadas, não pode pôr em risco a sobrevivência da estrutura global" (loc. cit.).

Como componente essencial do permanente processo de expropriações conduzido pela expansão incessante do capital em escala mundial, a constituição de uma superestrutura jurídica e de uma organização política em escala mundial visando a dominação de classe dos capitalistas foi posta em curso em sua atual configuração no mínimo desde o imediato pós-guerra na década de 1940. A constituição deste sistema buscou, por um lado, garantir o processo de dominação, para o que exigiu a reconfiguração das funções do estado, e por outro, o predomínio das decisões das organizações do capital sobre aquelas dos estados nacionais, que poderiam sofrer pressões das organizações dos trabalhadores, sob a tutela do estado capitalista mais poderoso e seus instrumentos de força como elementos garantidores da expansão do capital.

Sob a tutela dos Estados Unidos da América, em julho de 1944, antes mesmo do final da Segunda Guerra Mundial, representações de 44 países presentes na Conferência de Bretton Woods, realizada no estado norte-americano de New Hampshire, estabeleceram uma nova configuração econômica mundial, instituindo a moeda norte-americana como referência, objetivando a reconstrução do capitalismo pelo estabelecimento de regras financeiras e comerciais de escala mundial. Durante esta Conferência foram criadas instituições voltadas para a consecução de tal objetivo: o Fundo Monetário Internacional (FMI) e o 
sistema Banco Internacional para a Reconstrução e o Desenvolvimento (Bird ou Banco Mundial). O chamado sistema de Bretton Woods passa a obrigar os países a adotarem sua política monetária. A taxa de câmbio das diferentes moedas passa a ser mantida dentro de uma faixa, indexada ao dólar, cujo valor, naquele momento inicial, estava lastreado ao ouro. Porém, em 1971, ante a crise econômica e visando ampliar sua hegemonia, os EUA, de forma unilateral, decretaram o fim do padrão-ouro, cancelando a conversibilidade direta do dólar em ouro, mas impondo a permanência do dólar como referente da política monetária sob tutela destas organizações multilaterais.

Já ante a crise da década de 1970, após a reconstrução dos países europeus e da fase de crescimento econômico que havia gerado um ciclo de reconhecimento e atendimento de direitos básicos universalmente (o que se convencionou a chamar de estado de bem estar social), apresentaram-se os ajustes fiscais como estratégia de saída da crise e ativação de novo ciclo de expansão capitalista, com rebaixamento do valor do trabalho, ampliação da exploração e das expropriações a partir da interferência e "indicações" do $\mathrm{FMI}^{3}$ e Banco Mundial para o retorno do crescimento econômico capitalista. O desemprego é assumido agora como uma necessidade do capital para seu desenvolvimento. A criação do euro e os acordos de livre circulação de capitais também são estratégias decorrentes desta crise (MONTORO, 2016).

Nas décadas subsequentes, a política de ajustamento e as condicionalidades institucionais emanadas pelos organismos internacionais passaram a envolver, ao mesmo tempo, órgãos públicos de vários setores em diversos níveis de governo objetivando reorganizar por completo a estrutura do estado, alterando sua função. A ênfase na política macroeconômica e na reforma institucional tinha como finalidade central garantir o ajuste fiscal, visando garantir que os estados priorizassem os pagamentos do sistema da dívida pública.

A financeirização e o endividamento público e privado criados e ampliados pela aplicação das “recomendações” do FMI e BM - demonstrados pelos documentos oficiais da UE - foram responsáveis pela construção da crise econômica mundial de 2008, que repercute até hoje. A especulação levou grandes empresas e bancos estadunidenses a decretarem falência, frente ao que foi chamado de estouro da bolha imobiliária, ampliando o processo de concentração de capitais e destruição de forças produtivas, o que afetou economias em todo o mundo. O limite do endividamento e a iminência da impossibilidade de manter os pagamentos, bem como a "insegurança" de investimentos financeiros ${ }^{4}$ neste momento, modificaram o sistema da dívida em cada país, porém mantendo sua forma de funcionamento e ampliando seu alcance, supostamente justificando medidas de ajustes estruturais e ajustes fiscais recomendados pelo FMI e Banco Mundial e, no caso Europeu, assumidos pela União Europeia para que os estados-membros pudessem pagar seus "compromissos" com a dívida pública.

Assim, a crise de 2008 gira em torno do agravamento e aprofundamento da situação anterior e com ajustes e sanções ainda mais rígidas, o que está provocando em âmbito mundial um desmonte do que foi construído como políticas sociais garantidoras de direitos e com restrições e destruição do estado democrático de direito, onde este esteve constituído. A destruição das forças produtivas pelo desemprego e destruição de capital fixo, pelo deslocamento da força de trabalho, com as migrações forçadas, o rebaixamento de salários, os contratos flexíveis de trabalho ou aumento do trabalho sem contrato, o fim das 
leis trabalhistas e previdenciárias são ao mesmo tempo causa e consequência desta crise. Ainda, conjugamse a este processo as expropriações primárias de territórios e da natureza, um sistema de dívida pública (ampliando sua voracidade pela corrupção) e a ameaça constante de guerra como carro chefe para saída da crise e retorno do crescimento capitalista, ou seja, visando a manutenção e crescimento das taxas de lucro, contrapondo sua tendência à queda. De acordo com Montoro (2016),

se observa que este entramado gera uma bola de neve cada vez maior, que supõe um mecanismo privilegiado de transferência de recursos ao capital financeiro, financiado mediante os cortes de gasto público social, quer dizer, mediante a desvalorização da força de trabalho pela redução do salário indireto que constituem a educação ou a sanidade públicas. É uma modalidade déjà vu em outras regiões, como a América Latina, mas sua extensão à Europa é outro indicador da gravidade histórica da situação atual. (p. 639, tradução nossa)

Uma das consequências da crise estrutural é o desemprego crônico. Mészáros (2002, pp. 10041005) explica que o desemprego é também uma necessidade para o desenvolvimento capitalista e, portanto, uma tendência permanente deste sistema social, e que teve diferentes intensidades nos diferentes momentos de desenvolvimento social. Enquanto o desemprego, com sua funcionalidade ao sistema, podia ser um problema manejável e direcionado aos "bolsões de subdesenvolvidos", este não foi uma preocupação nos países centrais do sistema mundial do capital e a questão era designada ao indivíduo, que era responsabilizado pela sua má sorte. Posteriormente, passa a ser tratado como uma consequência da modernização industrial e da "substituição de trabalho não-qualificado pelo qualificado" e o problema também foi ignorado em prol de um futuro brilhante de consumo e apontado como um problema individual por ser consequência da não empregabilidade por falta de qualificação dos próprios trabalhadores desempregados.

O resultado desta tendência, no entanto, é um colapso social que atinge todos os trabalhadores, tanto os não-qualificados como aqueles altamente qualificados, nos países periféricos e nos países centrais do capitalismo. A isto chamamos de desemprego crônico e os jovens são fortemente atingidos, ocasionando uma perspectiva de futuro limitada e incerta. As desigualdades sociais se ampliam na mesma proporção em que aumenta a produção de capital e as expropriações exigidas neste processo.

\section{O Caso Espanhol}

A partir dos anos 2000 o desemprego passa a ser uma preocupação social maior, não só para os trabalhadores, mas também para as políticas de alguns estados. Tanto a União Europeia (UE), quanto seus países membros isoladamente, passam a reconhecer a crise econômica e o desemprego estrutural. No entanto, em seus discursos atribuem como causa questões como o abandono precoce da escola, a não formação profissional adequada ao dinâmico mercado de trabalho, motivos esses que geram problemas de empregabilidade. A análise dos documentos da UE e as estatísticas geradas por suas agências e organismos revelam a preocupação com esta realidade e apontam o que julgam serem as maiores debilidades ${ }^{5}$.

O principal desafio segue sendo a criação de postos de trabalho: em particular, Grécia e Espanha registram taxas de desocupação superiores a 25\%. A Comissão Europeia e os estados-membros colocaram em marcha um amplo leque de medidas para reorientar os 
desempregados para a educação, a formação e o emprego e fomentar um crescimento econômico sólido e duradouro. (COMISIÓN EUROPEA, 2015, p. 10, tradução nossa)

Pelos dados oficiais de 2015, o desemprego no âmbito da União Europeia foi de 16,7\% em geral e entre os jovens de 25\% (COMISIÓN EUROPEA, 2015). Segundo a UE, um dos objetivos principais da Comunidade Europeia é gerar mais crescimento econômico e mais empregos. Para isso, a UE criou o FSE (Fundo Social Europeu), que financia investigações, inovação e desenvolvimento tecnológico a fim de aumentar a competitividade europeia, além de investir em educação (especialmente formação profissional) e aprendizagem permanente (segundo demanda do mercado de trabalho).

Para os jovens, a estratégia delineada pela UE é o Programa Europeo de Educación ERAMUS+, que consiste em educação, formação profissional, primeiro emprego ou intercâmbio cultural/linguístico entre países da Europa para jovens menores de 25 anos, sendo a mobilidade o fundamento do Programa. Em 2018

\begin{abstract}
Seu orçamento é de 14 bilhões e 700 milhões de euros. Este programa permitiu estudar e aprender em outro país a mais de dois milhões de estudantes europeus no ensino superior e a mais de 600.000 estudantes na formação profissional. Segundo as cifras fornecidas na web da Comissão Europeia, se beneficiaram mais de 4 milhões de pessoas dos programas de mobilidade, mais de 500.000 do programa de voluntariado e intercâmbio e aproximadamente 25.000 estudantes dos másteres conjuntos. (PORTAL LOENTIENDO, jan. 2018, online, tradução nossa)
\end{abstract}

$\mathrm{Na}$ Espanha, a gestão do programa Erasmus+ está ao encargo do Servicio Español para la Internacionalización de la Educación (SEPIE), no âmbito da Educação e da Formação; e da Agencia Nacional Española (ANE), integrada ao Instituto de la Juventud (INJUVE). Apesar de o programa existir há 30 anos e ter um investimento alto e um público numeroso, o problema de desemprego juvenil persiste, o que é um importante elemento para reflexão.

Há análises da crise do emprego juvenil na Espanha que apontam duas situações opostas que geram um agravamento da situação atual do desemprego juvenil. De acordo com o relatório de um estudo da Fundación Novia Salcedo (ESPAÑA, 2013b), a OIT (Organização Internacional do Trabalho) relata dois tipos de desajuste das competências ${ }^{6}$ e utiliza os níveis de estudo como parâmetro das mesmas. O primeiro tipo consiste em um desajuste entre a oferta e a demanda de competências profissionais e se baseia em uma comparação entre os níveis de educação dos empregados e dos desempregados. O segundo tipo se refere ao desajuste entre as competências com que contam os jovens e as competências exigidas pelos postos que eles ocupam, o que se agrava com a defasagem da formação daqueles que estão em situação de desemprego de longa duração.

Naquele relatório se lê que a "sobreeducação e o excesso de competências coexistem com a subeducação e a escassez de competências” (ESPAÑA, 2013b, p. 13, tradução livre nossa). Segundo o relatório, este desajuste faz com que as soluções da crise do emprego juvenil sejam mais difíceis e lentas, pois afirma que quando os jovens empregados possuem mais competências que as exigidas para o posto que ocupam, não se está aproveitando seu valioso potencial e se está perdendo a possibilidade de melhorar a produtividade econômica, o que seria possível se estes jovens ocupassem postos de trabalho de acordo com seu nível de competências. Já os de níveis de formação inferior ficam ainda mais prejudicados e distantes do objetivo de 
conseguir um emprego. Por esta análise, fica evidente a culpabilização do jovem, esteja ele empregado ou desempregado, já que é ele que em um caso possui competências demais, noutro de menos.

$\mathrm{Na}$ Espanha o desemprego juvenil (jovens entre 16 e 25 anos) em 2017 foi de 37,46\% (INE, 2017). Segundo o Governo Espanhol (ESPAÑA, s/d, pp.11-12, tradução nossa), ao analisar as causas da situação de desemprego, além das circunstâncias derivadas da conjuntura econômica atual, existe um conjunto de debilidades estruturais que influenciam diretamente as estatísticas de desemprego jovem, tais como:

- Alta taxa de abandono escolar, o dobro dos valores da UE-27.

- Marcada polarização do mercado de trabalho, onde uns jovens abandonam seus estudos com escassa qualificação, enquanto outros são altamente qualificados e, no entanto, há subempregados nos dois polos.

- Escasso peso relativo da formação profissional de grau médio.

- Escassa empregabilidade dos jovens, especialmente relativo ao conhecimento de idiomas estrangeiros.

- Alta temporalidade, com $82,3 \%$ de jovens que trabalham de forma temporal involuntariamente.

- Alta contratação parcial não desejada, com $51 \%$ de jovens que trabalham de forma parcial a espera de um contrato a tempo integral.

- Difícil acesso ao mercado de trabalho dos grupos em risco de exclusão social, migrantes e refugiados são os mais discriminados.

- Necessidade de melhorar os níveis de autoemprego e iniciativa empresarial entre os jovens.

A estratégia demandada pelo capital para supostamente superar estas debilidades identificadas é a realização de parcerias público-privadas e a redução dos custos do trabalho para virtualmente aumentar as perspectivas de contratação dos jovens, a partir de subsídios do Governo espanhol e da própria UE. Para exemplificar: no período 2007-2013 a Espanha utilizou o financiamento do FSE em matéria de fomento do espírito empresarial e adaptabilidade, empregabilidade, inclusão social e igualdade de gênero, capital humano e cooperação transnacional e inter-regional. As medidas e políticas implementadas a partir das parcerias com financiamento encontraram como áreas prioritárias a formação e emprego, educação, alívio à pobreza e inclusão social (ESPAÑA, s/d). Entretanto, pela persistência do alto índice de desemprego juvenil, identifica-se que se atende às demandas do capital, porém não àquela dos jovens: conseguir emprego e ou seguir os estudos.

Dentre os membros da UE, a Espanha apresenta uma das proporções mais altas de jovens que nem estudam no sistema regular de educação, nem trabalham, nem recebem outro tipo de formação. Esta referência se popularizou na Espanha como "Ninis" . A taxa de Ninis entre 15-24 anos na Espanha só é superada na UE pela Bulgária e pela Itália, e fica em mais de cinco pontos da média UE: 12,2\% na UE-27 frente a 18,8\% na Espanha (ESPAÑA, 2013). Ou seja, 18,8\% de jovens nem estuda, nem trabalha, nem recebe formação, mesmo que somente $3,5 \%$ destes jovens desejem/optem estar nesta situação. 
Com os dados oficiais, declara-se que a partir das medidas tomadas os números de desempregados e de jovens em formação tem se alterado significativamente. Em dezembro de 2017 a situação do desemprego na Espanha apresentou uma redução interanual de 7,84\%. Durante o ano de 2017 se registraram 1,9 milhões de contratações indefinidas ${ }^{8}$, a maior cifra da última década, os contratos indefinidos a tempo integral cresceram $14,41 \%$ no conjunto de 2017 , o dobro dos contratos temporários. Ou seja, o que se evidencia em uma análise um pouco mais cuidadosa é que sob o manto dos contratos precarizados há uma maquiagem nos índices de desemprego, não sua efetiva redução.

Segundo o Servicio Público de Empleo Estatal os números de desempregados registrados nos órgãos de emprego são um total de 3.412.781 pessoas, 290.193 menos que o ano anterior. Os dados por setores econômicos demonstram que na agricultura se reduziu em 8.814 (-5,38\%); na indústria aumentou em 2.729 (+0,90\%); na construção se incrementou em $10.532(+3,47 \%)$; em serviços baixou em $51.280(-2,14 \%)$ e o coletivo Sem Emprego Anterior se reduziu em 14.667 pessoas (-4,78\%). Segundo este documento, a contratação indefinida dos menores de 25 anos (jovens), cresceu 20,1\% durante o ano de 2017. Novamente fica evidenciado que a contratação precarizada vela o desemprego, ao permitir considerar nas estatísticas como empregados aqueles que na realidade apenas estão com alguma tarefa temporária, geralmente por curtíssimo prazo, inferior a um mês.

Mesmo com a diminuição anunciada, é grave a situação de 3.412.781 de pessoas desempregadas na Espanha e entre esta população encontra-se 45\% de jovens. As medidas governamentais adotadas frente a estes dados são:

- Flexibilizações trabalhistas e rebaixamento salarial do conjunto dos trabalhadores, possibilitando ampliação dos postos de trabalho sem oneração ao capital.

- Subsídios com a previdência/seguridade para as empresas através das parceiras públicoprivadas.

- Compra pelo estado de serviços educacionais e de formação profissional fornecidos por empresas/instituições privadas, proporcionando um alongamento da escolarização e formação mitigando a desocupação.

- Alterações de legislações relativas à regulação do trabalho, da previdência e educacionais para permitir o repasse de maior parcela do fundo público às organizações privadas.

- Programas pontuais, como o Programa Garantía Juvenil.

$\mathrm{Na}$ atual configuração da União Europeia os países membros com situação mais preocupante podem acionar o FSE para apoio de programas assistenciais e de formação. A Espanha recorreu a este Fundo para estruturar o Programa Garantía Juvenil. Todas as ações de cooperação do FSE condicionam os empréstimos ou doação de recursos para realizar ações de superação de um problema social aos pacotes de ajustes ou exigências de adaptação às diretrizes de desenvolvimento da União Europeia, que por sua vez seguem as diretrizes do FMI e da OCDE. Um dos exemplos mais significativos é a reformulação da legislação educacional da Espanha, consubstanciada na Lei Orgânica para a Melhoria da Qualidade 
Educativa - LOMCE (Ley Orgánica para la Mejora de la Calidad Educativa - Ley Orgánica 8/2013, de 9 de diciembre).

A LOMCE faz parte das reformas assumidas pela Espanha junto ao pacote de ajuste e condutas assumidos com a União Europeia. A Lei consiste em itinerários flexíveis, com currículos que privilegiam matemática, escrita e língua estrangeira, com foco no rendimento escolar de forma meritocrática, tendo o PISA 9 como parâmetro de qualidade.

Bernal Agudo (2015) critica a LOMCE e a situa como a efetivação da política neoliberal no campo da educação espanhola.

\begin{abstract}
Se poderia dizer que as referências neoliberais assumiram, enfim, o mando da sociedade, como podemos ver com facilidade nos sete princípios que sustentam a LOMCE: simplificar o currículo e reforçar os conhecimentos instrumentais; flexibilizar as trajetórias de forma que os estudantes possam escolher as mais adequadas às suas capacidades e aspirações; desenvolver sistemas de avaliação externa, censitários e consistentes ao longo do tempo; incrementar a transparência dos resultados; promover uma maior autonomia e especialização nos centros; exigir aos estudantes, professores e colégios a prestação de contas e incentivar o esforço. (Op. Cit., p. 2, tradução nossa)
\end{abstract}

Tarabini e Montes (2015) também criticam as alterações para itinerários flexíveis que consistem em

\begin{abstract}
algumas mudanças curriculares introduzidas pela Lei, como a distinção entre disciplinas centrais comuns, específicas e de livre configuração; a supressão da Educação para a Cidadania; a perda de centralidade de disciplinas como música e artes plásticas; ou o desaparecimento dos ciclos educativos na educação primária [ensino fundamental] para voltar aos antigos cursos; mostram a centralidade que se atribui à dimensão instrumental da aprendizagem. (Op. Cit.,p.9, tradução nossa)
\end{abstract}

Para Tarabini e Montes (2015, p. 3, tradução livre nossa) três aspectos são cruciais na LOMCE, tomando como referência as evidências científicas internacionais: "os itinerários prematuros e a criação de vias de segunda oportunidade; o foco no rendimento acadêmico dos estudantes como medida do êxito escolar; e a omissão das estratégias preventivas para fazer frente ao Abandono Escolar Prematuro". Consideram a LOMCE controversa, entre outros aspectos, em relação ao abando precoce do sistema escolar, um dos motivos elencados pelos órgãos oficiais como causa do desemprego juvenil. Os autores consideram que a Lei omite esta questão e, portanto, é uma inflexão em relação à definição da agenda política espanhola de combate do Abandono Escolar Prematuro, reforçando assim, a segregação social e educacional. E ainda concluem que a Lei não auxilia a atingir as metas e diretrizes internacionais para educação.

Dentro do quadro de mudanças na legislação para alterar os processos educacionais, a criação de programas variados e, em geral, com caráter acelerado de formação profissionalizante é recorrente. O Programa Garantía Juvenill10 consiste em cursos profissionalizantes rápidos ${ }^{11}$, indicando mudanças na educação e na formação, com a vinculação entre formação e primeiro emprego. Este programa é desenvolvido pelo Ministerio de Empleo y Seguridad Social, que estabeleceu um processo de negociação com os Interlocutores Sociales ${ }^{12}$ para a elaboração da Estrategia de Emprendimiento y Empleo Joven 2013-201613, oferecendo subvenção e incentivos às empresas que contratam jovens desempregados. Empreendedorismo e autoemprego também 
são conceitos-chave deste Programa, proposto e financiado pela União Europeia para auxiliar a Espanha na diminuição do desemprego juvenil.

Seus objetivos passam por melhorar a empregabilidade dos jovens, aumentar a qualidade
e a estabilidade do emprego, promover a igualdade de oportunidades no acesso ao
mercado laboral e fomentar o espírito empreendedor. Os eixos sobre os que se apoia a
Estratégia são: incentivar a contratação e a iniciativa empresarial entre os jovens, adequar
a educação e a formação que recebem à realidade do mercado de trabalho e reduzir a taxa
de abandono escolar precoce. (CITA PREVIA INEM, 2016 14, online, tradução livre
nossa)

Apesar de ter um investimento elevado e um público numeroso, o problema do desemprego juvenil persiste, o que nos leva a confirmar que o problema estrutural não está na educação e na formação como é apresentado pela Comissão da União Europeia, mas sim na ausência de postos de trabalho e ou pela precariedade dos postos e formas de ocupação dentro da lógica de organização capitalista. Portanto, concordamos com o informe Juventud Necesaria: consecuencias económicas y sociales de la situación del colectivo joven ${ }^{15}$ — do Consejo de la Juventud de España (órgão que aglutina 76 entidades juvenis de todo o país) - que demonstra que esta geração está marcada pelo desemprego, pela precariedade, pela sobrequalificação em relação aos insuficientes postos de trabalho, pela emancipação tardia e pela migração forçada (CJE, s/d).

\section{O Caso Brasileiro}

O jovem desempregado no Brasil está imerso em uma realidade social fundada na limitação grave ou ausência de acesso aos serviços públicos que garantem direitos sociais básicos, como saúde, educação, moradia e também ao acesso à cultura e lazer, a espaços de socialização e de auto-organização. Em um país que é uma das maiores economias do mundo, há um enorme contingente populacional vivendo na miséria e em condições desumanizadoras na busca da produção de sua existência.

Avalia-se que o aumento do desemprego se relaciona com a ampliação das desigualdades sociais e da piora das condições de vida de grupos populacionais específicos (sexo, raça ou cor ${ }^{16}$, etário), como aponta o documento do IBGE (2017) intitulado Sintese de Indicadores Sociais: Uma análise das condições de vida da população brasileira: 2017.

Em 2016, segundo os dados do IBGE (2017, p. 25), o aumento da desocupação juvenil foi expressiva, em média 21,1\%, o que significa que entre os homens jovens atingiu 18,9\%, e, na categoria mulher de 16 a 29 anos a taxa de desocupação atingiu o nível mais alto dentre todos os grupos populacionais, com 24,0\% (2,2 milhões de jovens mulheres). O mesmo documento registra que há diferença nos percentuais de desempregados entre negros e brancos, e entre os níveis de escolarização, sendo mais atingidas as jovens negras com Ensino Médio incompleto.

No Brasil, quando visualizamos a ocupação das pessoas incluindo a separação por sexo, os dados do IBGE indicam claramente que o sexo mais vulnerável frente às consequências das crises são as mulheres. 
Gráfico 1 - Taxa de desocupação das pessoas de 16 anos ou mais de idade, segundo o sexo - Brasil - 2012-2016 Fonte: IBGE, 2017, p. 24, Gráfico 7

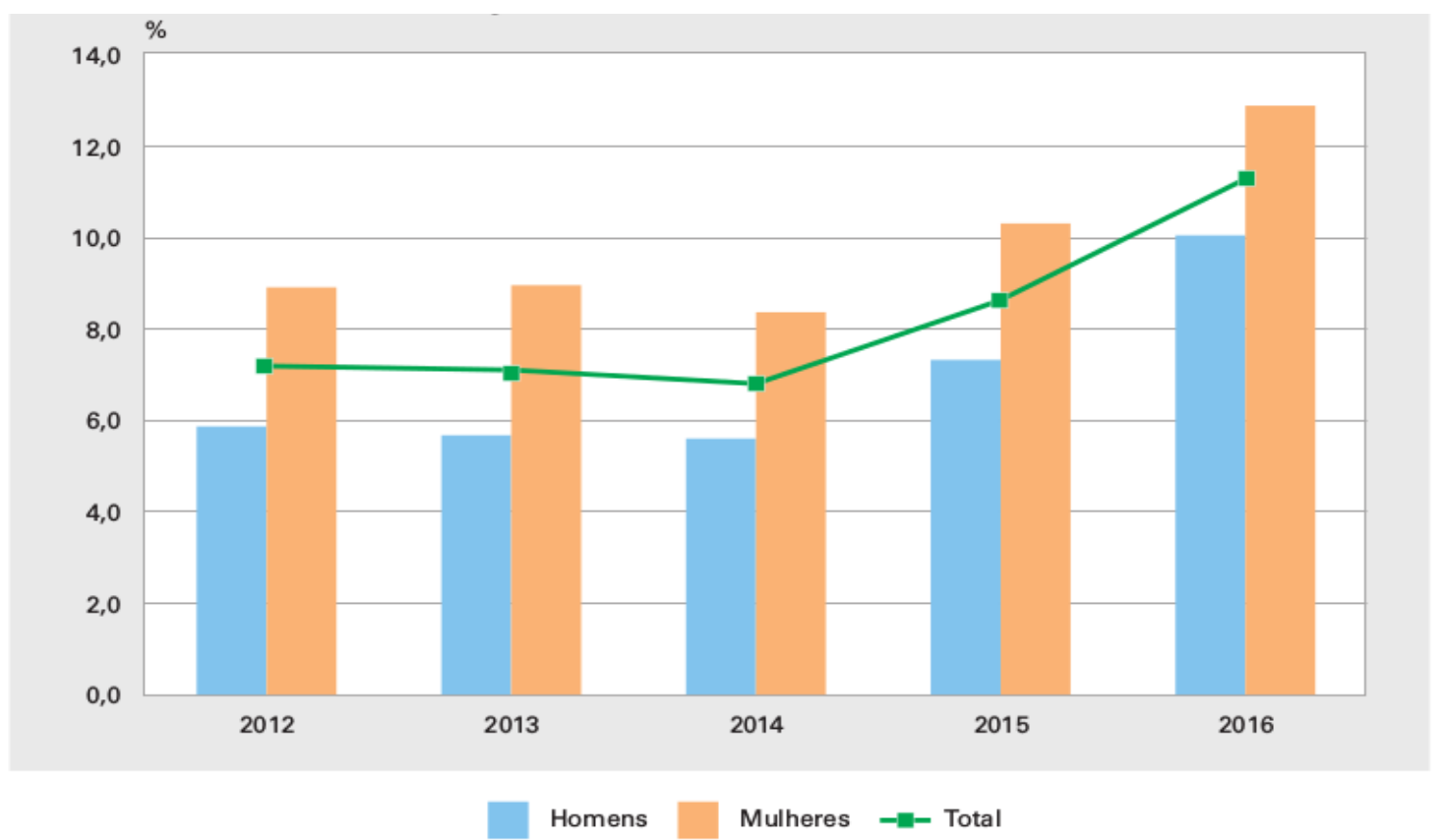

Como explicam os pesquisadores do IBGE (2017, p.24):

O crescimento da taxa de desocupação ocorreu também em todos os níveis de instrução, independentemente do grupo populacional [...]. Em 2012, a população branca registrou $5,8 \%$ contra $8,6 \%$ de pretos e pardos, enquanto, em 2016, as taxas subiram para $9,1 \%$ e $13,2 \%$, respectivamente. O detalhamento da taxa de desocupação revela ainda que as taxas de desocupação da população preta ou parda foram superiores às da população branca em todos os níveis de instrução. Os diferenciais foram menores conforme o maior nível de instrução, mas ainda assim, situaram-se em torno de 20,0\% nos níveis mais elevados. Na categoria ensino fundamental completo ou médio incompleto, o diferencial entre a taxa de desocupação de pretos e pardos vis a vis a de brancos atingiu seu máximo (Gráfico 8). 
Gráfico 2 - Taxa de desocupação das pessoas de 16 anos ou mais de idade, por cor ou raça, segundo os níveis de instrução - Brasil - 2016

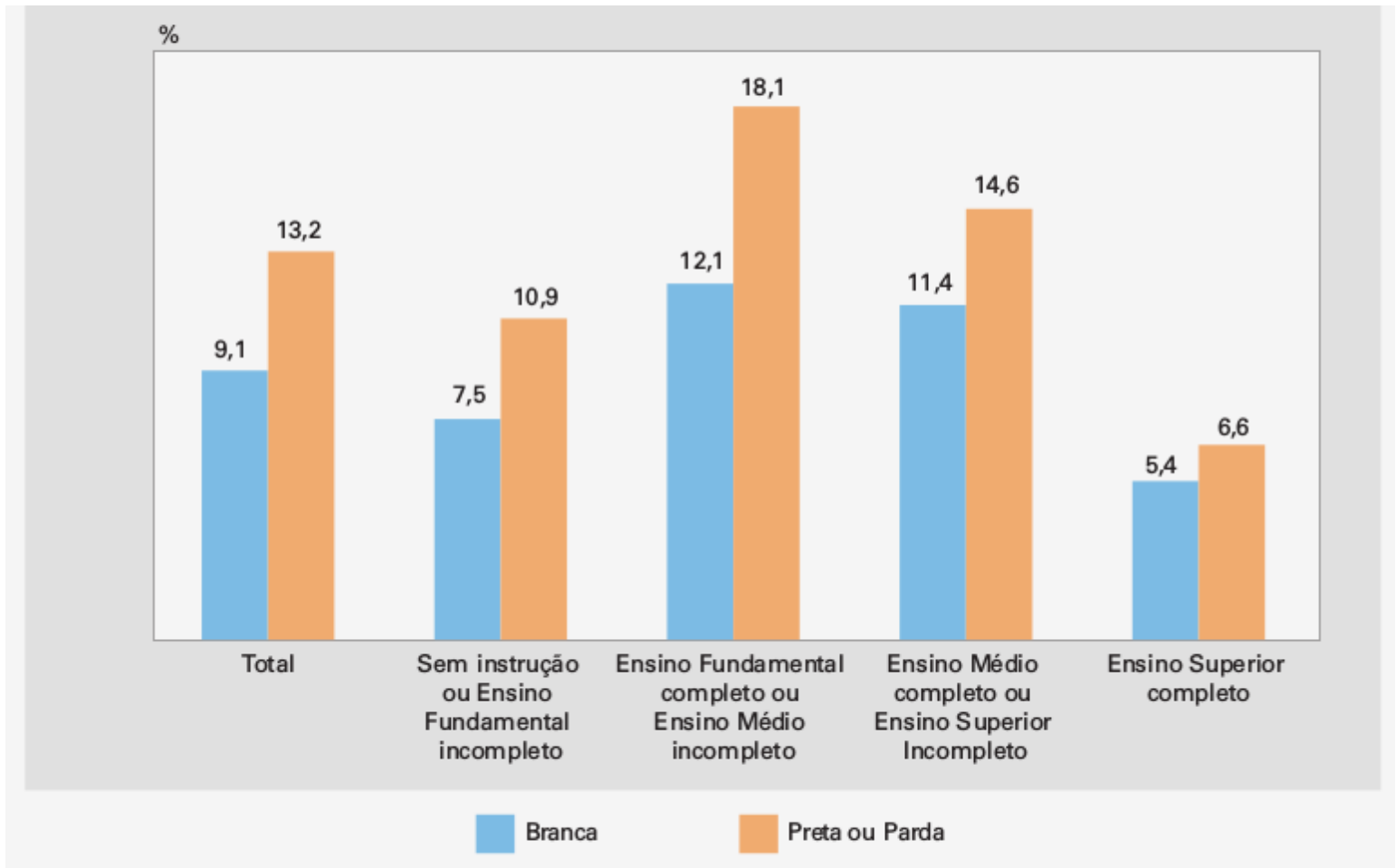

Fonte: IBGE, 2017, p. 25, Gráfico 8

Ao analisar os dados sobre a idade em que se começa a trabalhar no Brasil, novamente evidenciase a desigualdade entre sexos, cor e escolaridade. Segundo o IBGE (2017, p. 32), a idade em que o trabalhador começou a trabalhar tem forte relação com sua inserção no mercado de trabalho e com sua trajetória educacional, "já que a entrada precoce no mercado de trabalho pode inibir a sua formação escolar - quanto na obtenção de rendimentos mais elevados." Vê-se nos dados de 2016 que 39,6\% começaram a trabalhar com até 14 anos. "Para aqueles trabalhadores que não tinham instrução ou não completaram o ensino fundamental, o percentual subiu para $62,1 \%$, ao passo que para os trabalhadores com nível superior completo essa proporção caiu para 19,6\%."

Os dados acima corroboram com as conclusões de nossas pesquisas anteriores, bem como de outros pesquisadores como Leão e Nonato (2012), Silva, Quartiero e Evangelista (2012), Silva (2015), dentre outros: a inserção precoce no trabalho tem relação direta com os níveis de escolaridade, uma vez que o trabalho é um dos principais motivos de afastamento dos jovens da escola, criando um círculo vicioso em que por não terem condições de estudar, estes mesmos jovens terão sua inserção no mercado de trabalho nos níveis de menor remuneração.

Um olhar para essas trajetórias juvenis revela grande complexidade. Eles apresentavam, em seus percursos educacionais e ocupacionais, as marcas de uma infância empobrecida. Ainda não haviam completado o ensino fundamental e a maioria ocupava postos de trabalho precários e com baixa qualificação ou estavam desempregados. [...] Os jovens apresentavam, assim, a experiência da inclusão subalterna que marca o modelo de modernização econômica e social vivida na sociedade brasileira (...). (LEÃO E NONATO, 2012, p. 836) 
Assim como observado no caso espanhol, no Brasil também o percentual de jovens (16 a 29 anos) que nem estudavam nem estavam ocupados é muito alto, ainda que os índices estejam abaixo. Os denominados “nem-nem" aumentaram de 2014 (22,7\%) para 2016 (25,8\%). Novamente trabalho e escolaridade se cruzam: em 2016, a maioria dos jovens "nem-nem" se encontrava entre aqueles com o ensino fundamental incompleto ou equivalente $(38,4 \%)$.

Quando incluída a questão racial, identificamos nos dados do IBGE (2017) que o percentual de jovens “nem-nem” em 2016 era maior entre aqueles de cor ou raça preta ou parda (29,1\%) do que entre os brancos $(21,2 \%)$. Com a questão de gênero e raça ou cor, a situação fica ainda mais dramática entre as mulheres pretas ou pardas (37,6\%). Ao considerar o gênero, a diferença entre o percentual de homens e o de mulheres “nem-nem" foi de 13,7 pontos percentuais, ou seja, as mulheres apresentam quase o dobro de chances (1,7 vezes mais chances) do que os homens de se encontrarem na condição de nem estudarem e nem terem ocupação remunerada.

Ainda segundo o IBGE, a diferença entre o percentual de jovens homens não-estudantes e nãoocupados e o jovens mulheres na mesma situação se acentua nos grupos mais velhos, já que entre os homens $16,6 \%$ não estudavam nem estavam ocupados, enquanto entre mulheres o percentual era de $34,6 \%$, na faixa etária de 25 a 29 anos de idade para ambos os sexos.

Entretanto, contrariando o senso comum, os jovens que se encontram em tal situação assim estão não por falta de interesse ou por inação. Entre os "nem-nem" do sexo masculino prevaleciam os que estavam procurando e se dispunham a começar a trabalhar imediatamente em uma ocupação $(52,3 \%)$, enquanto entre as mulheres a taxa era ainda maior (69,7\%). Para compreender este contexto vivido pelos jovens brasileiros, a explicação dos pesquisadores do IBGE é importante ao detalhar que entre os jovens que não estudavam nem estavam ocupados o percentual dos homens procurando e disponíveis para trabalhar em uma ocupação oscilou entre 41,9\% (2012) e 45,9\% (2015) e chegou a 52,3\% (2016), enquanto o das mulheres ficou entre 21,7\% (2012) e 25,7\% (2015) e foi de 30,3\% (2016). Ao serem instados a responder sobre os motivos de estarem nesta situação, 34,6\% das mulheres responderam "ter que cuidar dos afazeres domésticos, do(s) filho(s) ou de outro(s) parente(s)" e apenas 1,4\% dos homens apontaram tal motivo como principal, o que demonstra a desigualdade de gênero em relação a determinadas ocupações. Entre mulheres jovens que não estudavam nem estavam ocupadas, 92,1\% responderam realizar tarefas de cuidados a moradores do domicílio ou parentes e afazeres domésticos no domićlio, enquanto 61,3\% dos homens tenham alegado tal motivo.

Outro elemento importante é que cerca de $60 \%$ da população considerada pobre pela linha de 5,5 dólares por dia vivem sem pelo menos um dos três serviços de saneamento básico - abastecimento de água por rede geral, esgotamento sanitário por rede coletora ou pluvial e coleta direta ou indireta de lixo. Entre a população abaixo da linha de 5,5 dólares por dia, o percentual dos que viviam sem pelo menos um dos três serviços de saneamento básico era ainda maior (59,6\%) do que para o total da população (37,9\%). Evidenciase que os jovens submetidos a esta situação e que se encontram na situação de "nem-nem”, diferentemente da maioria dos jovens espanhóis "ninis", tem suas possibilidades de vida e desenvolvimento humano muito 
mais limitadas, por estarem inseridos em ambientes de maior precariedade que não propiciam ou pouco propiciam condições para seu desenvolvimento humano.

Diante desta conjuntura de desemprego e desigualdade social o governo brasileiro segue o percurso da Espanha para duas políticas de grande incidência para a juventude, a saber o ensino médio e o ProJovem.

O ensino médio até hoje não se universalizou, mesmo que desde 2009, com a Emenda Constitucional $N^{\circ}$ 59/2009, foi instituída constitucionalmente a universalização da educação infantil até o ensino médio, estabelecendo a obrigatoriedade escolar de crianças e jovens em idade de 4 a 17 anos (BRASIL, 2009). As demandas da reestruturação produtiva do capital vêm motivando um conjunto de leis, resoluções, decretos, emendas, que resultaram em inúmeras mudanças nos cursos de nível médio, que vão desde pedagógica até organizacionais, as quais buscam soluções rápidas e pragmáticas, tanto para as escolas quanto para o futuro dos jovens.

Destaca-se que essas formulações têm sido influenciadas pela sociedade civil e pelos aparelhos privados de hegemonia, como as organizações dos empresários (FIESP, CNI, SESI, SENAI, SENAC, SENAR) que tem assumido lugar privilegiado na definição de políticas educativas, relacionando melhores índices de rendimento escolar com melhor produtividade do trabalho, ou seja, o conceito de empregabilidade está arraigado nas reformulações da política do ensino médio no Brasil.

Segundo Rummert, Algebaile e Ventura (2012), as mudanças educativas em curso no Brasil desde 1990, com a promulgação da Lei de Diretrizes e Base da Educação (LDB) nº 9.394/96 (BRASIL, 1996), possuem um "caráter largamente flexível" e estão intimamente ligadas às orientações realizadas pelo Banco Mundial, aspecto que reforçou a "ausência de um verdadeiro sistema nacional de educação", aspecto que favoreceu posteriormente a regulamentação e ampliação de "ofertas educativas fragmentadas como alternativa de formação para a classe trabalhadora" (RUMMERT, ALGEBAILE E VENTURA, 2012, p. 37).

Kuenzer (2010), ao analisar a dualidade dos cursos de ensino médio entre formação geral e formação profissional, destaca que ela não pode ser entendida apenas como uma questão pedagógica, mas sim estrutural, fundada no modo de produção capitalista, resultado de um processo social e histórico determinada pelas contradições entre trabalho e capital.

A divisão entre trabalho intelectual e trabalho prático, que por muito tempo justificou duas redes de ensino médio, uma de educação geral para a burguesia e outra profissional para os trabalhadores, tem origem na separação entre a propriedade dos meios de produção e a propriedade do trabalho [...] a superação da dualidade não é uma questão a ser resolvida através da educação, mediante novas formas de articulação entre o geral e o específico, entre teoria e prática, entre disciplina e transdisciplinaridade. (KUENZER, 2010, p. 862).

No Brasil, o Decreto $N^{\circ} 2208 / 1997$, o qual definiu objetivos e reformulou a educação profissional, separou a educação profissional e tecnológica do ensino médio, interrompendo "uma trajetória histórica construída desde os anos de 1940 pelas escolas técnicas federais, que se caracterizavam por ofertar educação profissional pública e de qualidade, permitindo com isso aos jovens o acesso ao emprego e ao ensino superior" (KUENZER, 2010, p. 864). Para Kuenzer o discurso da democratização do ensino e da ampliação 
da oferta dos cursos de nível médio de educação geral, que na sua forma atual, está direcionada aos jovens da classe trabalhadora, vem sendo realizadas de maneira desqualificada (Op. Cit., p. 865). Neste modo, a inversão da dualidade "é a nova realidade da escola média para os trabalhadores, que tem como alternativa a modalidade de educação geral". Em 2004 o Decreto No 5154/2004 revoga o Decreto No 2208/1997. Em 2014 há alterações no Decreto de 2004 dadas pelo Decreto 8268/2014, e mantém-se a possibilidade de oferta de educação profissional de nível médio de forma integrada, concomitante ou subsequente ao ensino médio, recuperando a autorização legal para diferentes formas de organização dos processos de formação profissionalizante relacionadas ao ensino médio.

Para Kuenzer (2000, p. 16), a proposta de ensino médio, desde sua origem, está em sintonia com uma concepção de educação "orgânica ao modelo econômico em curso. As mudanças ocorridas no mundo do trabalho, associadas ao modelo de acumulação flexível e pautada pela "polarização das competências" tem demandado a formação de um trabalhador de "novo tipo", dotado de capacidades individuais de adaptabilidade, iniciativa, criatividade e flexibilidade, características que podemos reconhecer desde a proposta de ensino médio de 1997, na proposta de 2009 e atualmente a partir da Lei no 13.415 , de 16 de fevereiro de 2017.

As experiências pilotos testadas nas propostas de ensino médio de 2009 consistiam em um currículo com base comum - rudimentos do conhecimento e habilidades atitudinais - e uma parte variável que se aproximasse das demandas locais, ou seja, pela aproximação e conformação dos arranjos educativos aos arranjos produtivos locais. Sob a aparência de atender o anseio dos jovens e as demandas da sociedade contemporânea tem-se como ideia-chave a parceria e flexibilidade curricular. Para nós, no entanto, um currículo flexível, focado nos rudimentos do conhecimento e nas habilidades atitudinais, voltado ao espontaneísmo como solução para tornar a escola mais "atraente" aos jovens, procura capturar a subjetividade do indivíduo antes mesmo da sua inserção no mundo do trabalho, propalando valores que procuram justificar o sociometabolismo do capital na fase de intensificação da barbárie, como bem expressa - em claras linhas - o Banco Mundial, quando afirma que a educação é um elemento-chave para os indivíduos adaptarem-se, suportarem choques econômicos e a viver com oscilações de renda (WORLD BANK, 2011).

A atual reforma do ensino médio, imposta pela Lei no 13.415, de 16 de fevereiro de 2017, consiste em ampliação progressiva da carga horária para mil e quatrocentas horas, a fim de estimular uma escola em tempo integral, e se pauta (assim como a LOMCE espanhola) na possibilidade de o estudante cursar diferentes itinerários formativos supostamente de acordo com seus interesses e vocação. De acordo com esta nova Lei os componentes curriculares obrigatório deverão ocupar o máximo de $60 \%$ da carga horária e são eles português, matemática e inglês, os demais componentes curriculares serão optativos ( $40 \%$ da carga horária) e o sistema de ensino será responsável pela viabilização dos arranjos escolares a partir da Base Nacional Comum Curricular.

As estratégias consistem em ocupar a juventude que não tem perspectiva de emprego através do alongamento do tempo escolar e das possibilidades de realizar cursos e projetos aligeirados tendo em vista 
um primeiro emprego e ascender à qualidade de empregável. Dentro deste último caso e na mesma ótica a política em voga é o ProJovem.

Segundo a definição presente no próprio programa, o ProJovem visa ampliar o atendimento aos jovens de 15 a 29 anos que estão fora da escola, reintegrando-os ao processo educacional, promovendo qualificação profissional e assegurando o acesso a ações de cidadania, esporte, cultura e lazer (BRASIL, 2007). Foi criado a partir da integração de seis programas já existentes: Agente Jovem, Saberes da Terra, ProJovem, Consórcio Social da Juventude, Juventude Cidadã e Escola de Fábrica, e atende cerca de 467 mil jovens.

O Programa se subdivide em quatro modalidades: ProJovem Adolescente, ProJovem Urbano, ProJovem Campo e ProJovem Trabalhador. A sua gestão é compartilhada entre a Secretaria-Geral da Presidência da República e os Ministérios do Trabalho e Emprego, da Educação, e do Desenvolvimento Social e Combate à Fome, além das parcerias com os IFETS e o Sistema S. Estas modalidades consistem em:

1. ProJovem Adolescente: Consiste em estender o benefício de $\mathrm{R} \$ 30,00$ para famílias com direito a Bolsa Família que tenham jovens na faixa etária de 15 a 17 anos e que este benefício não exceda a dois benefícios $(\mathrm{R} \$ 60,00)$.

2. ProJovem Urbano: Os critérios para participar do programa: ter entre 18 e 24 anos; saber ler e escrever; estar fora da escola e não ter conclú́do o Ensino Fundamental. Pode estar empregado ou desempregado. O cursista receberá um auxílio de $\mathrm{R} \$ 100,00$ mensais e deve participar dos cursos de formação técnica que duram 18 meses. A qualificação profissional é ofertada e certificada pelo Serviço Nacional de Aprendizagem Comercial ou Serviço Nacional de Aprendizagem Industrial (Senac e Senai).

3- ProJovem Campo: O Programa modifica o Saberes da Terra e tem como objetivo elevar a escolaridade dos jovens da agricultura familiar (15 a 29 anos), com a conclusão do Ensino Fundamental, em regime de alternância dos ciclos agrícolas, com qualificação e formação profissional. O valor recebido é $\mathrm{R} \$ 50,00$ mensais e a duração dos projetos de escolarização são de 24 meses. Os projetos de EJA e a qualificação profissional são ofertadas e certificadas em parcerias com os IFETS, a Emater, a Embrapa e o Serviço Nacional de Aprendizagem Rural (SENAR).

4- ProJovem Trabalhador: É unificação dos programas Consórcio Social da Juventude, Juventude Cidadã e Escola de Fábrica e visa a qualificação profissional, desenvolvimento humano e facilitar a inserção no mundo do trabalho. Os critérios de participação são estar desempregado, estar matriculado no Ensino Médio, Fundamental ou em cursos de Educação de Jovens e pertencer a famílias com renda per capita de até meio salário-mínimo. O auxílio é de R \$ 100 mensais durante seis meses. O programa possui 600 horas, sendo 350 de qualificação profissional; 100 de desenvolvimento humano; 100 de reforço escolar e 50 de inserção no mercado na forma de estágio. A qualificação profissional é ofertada e certificada pelo Serviço Nacional de Aprendizagem Industrial (SENAI).

A lógica de parcerias público-privadas está na raiz deste Programa, que funciona com subvenção estatal de forma privatista, sob dois aspectos: a formação subalterna da classe trabalhadora de acordo com as necessidades do mercado de trabalho, tanto para o emprego como para o desemprego; e no investimento 
de recursos público no setor privado, barateando assim a força de trabalho e lucrando com os caros cursos de formação oferecidos ao programa como o faz o Sistema S, por exemplo.

A preocupação com a formação profissional e a inserção dos jovens no mercado de trabalho está pautada na preparação para o trabalho simples (como pode ser visto no catálogo de cursos) para a busca de um primeiro emprego ou a possibilidade de empreender, a partir de prestações de serviços por conta própria. Aqui também as cifras e os números de vagas são expressivos e, no entanto, não resolvem o problema do desemprego juvenil.

Assim, concordamos com Silva e Quartiero (2015, p.11):

Consideramos que o Programa Nacional de Inclusão de Jovem (Projovem) e, em particular a modalidade Projovem Trabalhador, contém traços que, longe de promover o trabalho concreto, entendido como possibilidade de humanização do homem, parece reafirmar as condições de trabalho marcadas por percursos profissionais precários e provisórios.

Há estudos como os de Silva (2015) que demonstram que a partir destes programas os jovens criam a ilusão de que é necessário estar sempre em formação para ser empregável, tendo assim sempre em vista um plano B, C, D, etc. como saída de emergência para enfrentar o problema que acreditam ser seu, mas na realidade é estrutural, de desemprego crônico. Com isso, a formação propiciada na forma demandada pelo capital cumpre o objetivo por este esperado: obnubilar as relações sociais que geram o desemprego, a ampliação das desigualdades, a piora das condições de vida e a retirada de direitos, fazendo com que parte significativa dos jovens se culpabilizem por sua situação e aceitem ocupar seu tempo em extenuantes cursos fragmentados e aligeirados e projetos a serviço da lucratividade do capital.

\section{Considerações Finais}

Este estudo não pretende ser um comparativo entre Espanha e Brasil, mas buscou demonstrar como em realidades sociais distintas apresentam-se problemáticas que possuem regularidades nas medidas indicadas pelo capital e seus aparelhos privados de hegemonia e governos. Portanto, optamos por verificar como a situação real tem ampliado as desigualdades sociais e desencorajado os jovens a pensarem no futuro nos dois países.

Ser jovem desempregado na Espanha ainda é uma condição diferente de ser jovem desempregado no Brasil, onde o grau de pobreza e desigualdade social é indicador de privação de questões básicas de sobrevivência.

O desemprego crônico é um problema estrutural, complexo e de difícil, senão impossível, resolução dentro da sociedade capitalista. No entanto, muitas análises e políticas deslocam o central do problema para questões vinculadas à educação e a formação, atribuindo ao sujeito a responsabilização pela sua situação social. Estas políticas também estão permeadas de uma lógica privatista através das parcerias público-privadas tanto dentro do sistema formal de educação (LOMCE e Ensino Médio) como na educação informal (Garantía Juvenil e ProJovem). 
Assim, tanto a LOMCE como a proposta de reforma do ensino médio brasileiro se pautam na negação do conhecimento mais elaborado e avançado aos jovens estudantes da classe trabalhadora, ampliando a fragmentação e fragilização do currículo, além de reforçar a perspectiva dualista da escola entre os diferentes extratos sociais, ampliando a desigualdade social e escolar/educacional.

As estratégias e investimentos governamentais não tem dado conta de resolver a situação, pois o problema é estrutural e endêmico do sistema do capital e o caráter focal das políticas em voga não são suficientes sequer para amenizar a situação, quando muito criam ilusões de que se está buscando soluções. Estas políticas logram ocupar a juventude que não tem perspectiva de emprego através do alongamento do tempo escolar e da realização de cursos ou participação em projetos de formação profissional, criando a persistente ilusão de que na busca do primeiro emprego, se não lograr vaga, ainda restam saídas caso estejam na qualidade de empregável, e para atingir tal qualidade depende do esforço do próprio jovem. Ou, ainda mais, que podem empreender e gerar seu autoemprego. No entanto, o que se evidencia tanto pelas expectativas dos jovens, que acabam sendo frustradas, quanto pela persistência dos índices elevados de desemprego e desocupação, como no caso dos jovens “nem-nem”, é que pensar soluções de problemas estruturais com medidas conjunturais e superficiais na forma de parcerias público-privadas e pela ampliação da destinação dos recursos do fundo público às instituições privadas só pode ampliar as condições sociais que geram a desigualdade e o desemprego, e não mitigá-las ou superá-las.

As expectativas de futuro dos jovens são desenvolvidas e elaboradas neste contexto, o que impacta seus projetos e suas atividades no momento atual. Os próprios jovens manifestam claramente que as péssimas condições de trabalho e os poucos e precários postos de trabalho existentes não lhes instigam a quererem projetar um futuro a longo prazo, mas impõem-lhes um pesado presente de trabalho simples e degradante que lhes tolhe as energias que poderiam utilizar no estudo e ou no trabalho rico de sentido, estes últimos ausentes da realidade da maioria. No Brasil e na Espanha os próprios jovens expõem esta situação, como está expresso pelo Consejo de la Juventud de España ao indicar que esta geração está marcada pelo desemprego, pela precariedade, pela sobrequalificação em relação aos insuficientes postos de trabalho, pela emancipação tardia e pela migração forçada. No Brasil agrava-se a situação dos jovens pela relação do tráfico, da violência urbana, da prostituição, das chacinas cometidas pelo estado, da intervenção militar, da criminalização das lutas sociais.

Para os jovens que precisam de políticas sociais que primem por sua formação dentro de uma perspectiva de emancipação humana, que garantam a apropriação da riqueza material e espiritual humana para uma vida digna e plena em sua humanidade, tais projetos não servem. Esses projetos referidos ao longo deste artigo ou ampliam as ilusões ou encaminham para formas degradantes de inserção no trabalho, em uma competição constante com sua própria humanidade (que lhe é negada ao culpabilizá-lo por sua situação social) e com os demais jovens e adultos trabalhadores, que são vistos como responsáveis por sua situação já que concorrem pelas poucas oportunidades existentes.

Assim, a necessidade de poder viver dignamente e de acessar uma educação pública que viabilize a apropriação do conhecimento científico, da filosofia, da arte, da cultura, do esporte, do lazer etc. impõe aos jovens outra necessidade: de organizar-se coletivamente e com autonomia, construindo espaços de 
esperança dentro dos estreitos limites de que dispõem, pois cada vez mais fica evidente que isso não será uma concessão do sistema destrutivo do capital. Assim, coletivamente poderão criar as possibilidades que lhes impulsionem a pensar e projetar o futuro de forma mais segura e concreta.

\section{Referências}

BERNAL AGUDO, José Luis. Análisis crítico del modelo de evaluación de la LOMCE. Avances en Supervisión Educativa, (23). 2015. Disponível em

< https://avances.adide.org/index.php/ase/article/view/27/28>, acesso em 12 Fev. 2018.

BRASIL. Emenda Constitucional $\mathbf{n}^{\circ}$ 59, de 11 de novembro de 2009. Prever a obrigatoriedade do ensino de quatro a dezessete anos. Diário Oficial da União, Brasília, DF, 11 de nov. de 2009. Disponível em: <http://www.planalto.gov.br/ccivil_03/constituicao/emendas/emc/emc59.htm> Acessado em: 20 jan. 2018.

BRASIL. Lei $\mathbf{n}^{\circ}$ 9.394, de 20 de dezembro de 1996: Estabelece as diretrizes e bases da educação nacional. Diário Oficial da União, Brasília, DF, 23 dez. 1996. Disponível em:

<http://www.planalto.gov.br/CCIVIL_03/leis/L9394.htm>. Acesso em: 15 jan. 2018.

BRASIL. Secretaria de Governo - Presidência da República. Projovem. Brasilia. 2007. Disponível em : $<$ http://www.secretariadegoverno.gov.br/noticias/2007/09/not02 05092007> , acesso em: 09/02/2018.

CJE - Consejo de la Juventud de España. ¿Cómo está el tema sobre políticas públicas de juventud? s/d. Disponível em < http://www.cje.org/en/our-work/politicas-publicas-de-juventud/como-esta-eltema/como-esta-el-tema-sobre-politicas-publicas-de-juventud/>, acessado em 09/02/2018.

COMISÍON EUROPEA. Compreender las políticas de la Unión Europea: la unión económica y monetária y el euro. Luxemburgo: Oficina de Publicaciones de la Unión Europea, 2015.

CONDE, Soraya Franzoni; MARCASSA, Luciana Pedrosa; TITTON, Mauro; VENDRAMINI, Célia Regina. Escola, trabalho e perspectiva de futuro de jovens estudantes. Revista Ibero-Americana de Estudos em Educação, v. 12, n. 4, out./dez. 2017.

ESPAÑA. Ministerio de Empleo y Seguridad Social. Nota de Prensa del Gabinete de Comunicación. Madrid: s/d. Disponível em

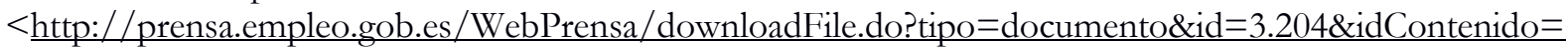
$2.825>$, acessado em 05/02/2018.

ESPAÑA. Ministério de Sanidad, Servicios Sociales e Igualdad. Plan Nacional de Implantación de la Garantía Juvenil en España. Madrid, 2013. Disponível em

$<$ http://www.empleo.gob.es/ficheros/garantiajuvenil/documentos/plannacionalgarantiajuvenil_es.pdf $>$, acessado em 12/01/2018.

ESPAÑA. Ministério de Sanidad, Servicios Sociales e Igualdad. Situación actual del empleo juvenil en España. Equipo de Investigación: Fundación Novia Salcedo. Bilbao, 2013b. p.58. Disponível em: <http://www.injuve.es/sites/default/files/Estudio\%20situacion $\% 20$ actual $\% 20$ del $\% 20$ empleo $\% 20$ juvenil $\% 20$ en $\% 20$ Espa $\%$ C3\%B1a.pdf>, acesso em 12/01/2018.

FONTES, Virgínia. O Brasil e o Capital Imperialismo: teoria e história. 2 ed. Rio de Janeiro: EPSJV/Editora UFRJ, 2010.

IBGE. Instituto Brasileiro de Geografia e Estatística. Síntese de indicadores sociais: uma análise das condições de vida da população brasileira: 2017/IBGE, Coordenação de População e Indicadores Sociais. Rio de Janeiro: IBGE, 2017.

INE. Instituto Nacional de Estadistica. Tasas de Paro. 2017. Disponível em $<$ http://www.ine.es/infografias/tasasepa/desktop/tasas.html?t=0\&lang=es $>$, acessado em $22 \mathrm{de}$ fevereiro de 2018. 
KUENZER, Acácia Z. O Ensino Médio agora é para vida: entre o pretendido, o dito e o feito. In: Educação \& Sociedade, v. 31, n. 70 - Campinas -SP, 2000.

KUENZER, Acácia Z. O Ensino Médio no Plano Nacional de Educação 2011 - 2020: superando a década perdida? In: Educação \& Sociedade, v. 31, n. 112 - Campinas, 2010.

LEÃO, Geraldo; NONATO, Symaira Poliana. Políticas públicas, juventude e desigualdades sociais: uma discussão sobre o ProJovem Urbano em Belo Horizonte. Educação e Pesquisa, São Paulo, v. 38, n. 04, p. 833-848, out./dez., 2012.

MÉSZÁROS, István. Para além do Capital. São Paulo: Boitempo, 2002.

MONTORO, Xabier Arrizabalo. Capitalismo y Economia Mundial: bases teóricas y análisis empírico para la compreensión de los problemas económicos del siglo XXI. 2 ed. Madrid: IME/ARCIS/UdeC, 2016.

PORTAL LOENTIENDO. Erasmus+, más oportunidades de empleo en 2018.Disponível em < https://loentiendo.com/erasmus-plus/>, acessado em 08 de janeiro de 2018.

RUMMERT, Sônia Maria; ALGEBAILE, Eveline; VENTURA, Jaqueline. Educação e formação humana no cenário de integração subalterna no capital-imperialismo. In: SILVA, Mariléia Maria da; QUARTIERO, Elisa Maria; EVANGELISTA, Olinda (organizadoras). Jovens, trabalho e educação: a conexão subalterna de formação para o capital. Campinas: Mercado das Letras, 2012, p.15-70.

SILVA, Mariléia Maria da; QUARTIERO, Elisa Maria. Jovens Pobres no Município de Florianópolis: Trabalho, Qualificação e Precariedade. 2015. Disponível em

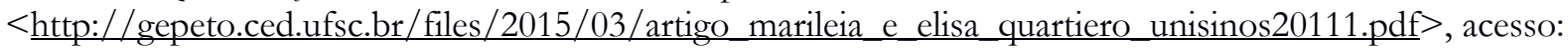
$09 / 02 / 2018$.

SILVA, Mariléia Maria da; QUARTIERO, Elisa Maria; EVANGELISTA, Olinda (Orgs). Jovens, trabalho e educação: a conexão subalterna de formação para o capital. Campinas: Mercado das Letras, 2012.

SILVA, Mariléia Maria da. Entre "plano b" e "saídas de emergência”: percursos e expectativas profissionais de jovens trabalhadores/as. IN: Revista Trabalho Necessário, ano 13, número 21. RJ: UFF 2015. Disponível em:http://www.uff.br/trabalhonecessario/images/TN_21/6_Artigo.pdf acesso em: $29 / 2 / 2016$

TARABINI, A., MONTES, A. La agenda política contra el abandono escolar prematuro en España: la LOMCE contra las evidencias internacionales. Avances en Supervisión Educativa. Revista $n^{\circ}$ 23. Junio, 2015.

WORLD BANK. World Bank consultations on the new education sector strategy for 2010-2020 in Brazil. 2011. Disponível em: < www.worldbank.org $>$ Acessado em: 11 de junho de 2017.

ZUCK, Débora Villetti. Educação na América Latina: desigualdade e reforma educativa no Brasil, Chile, México e Venezuela. In: Anais do $6^{\circ}$ Seminário Nacional Estado e Políticas Sociais. 2014.

Disponível em < http://docplayer.com.br/11362384-Educacao-na-america-latina-desigualdade-e-reformaeducativa-no-brasil-chile-mexico-e-venezuela.html>, acesso em 02 de setembro de 2017.

\footnotetext{
Notas:

1 Doutor em Educação. Professor do Departamento de Metodologia de Ensino do Centro de Ciências da Educação da UFSC. ORCID: Email: m.titton@ufsc.br

${ }^{2}$ Doutora em Educação. Professora do Departamento de Estudos Especializados em Educação do Centro de Ciências da Educação. ORCID: Enail: d.agostini@ufsc.br

3 Segundo Montoro (2016), a expansão do ajuste fundomonetarista na Europa pode ser verificada nas análise dos documentos 'Acta Única para la libre circulación de capitales' (1986-1993); el 'Tratado de Maastricht' (1993-1999 - criação do euro); El 'Pacto de Estabilidad y Crescimiento’ do Consejo Europeu en Amsterdã (1999-2007 e reforçado desde 2011).

4 Insegurança pode ser considerado um eufemismo do capital para tratar da impossibilidade de manutenção da remuneração dos capitais especulativos sem que haja o aprofundamento do processo de exploração e expropriação.
} 
5 No âmbito educacional o parâmetro oficial de análise é o PISA. Em média 20\% dos jovens da UE não alcançam níveis mínimos de competência de leitura, matemática e ciências. Os documentos apontam como ambiciosa a meta de diminuir para $15 \%$ ou menos esse dado até 2020. Seis milhões de jovens abandonam o sistema escolar, a meta é reduzir a menos de $10 \%$. Pretende-se que pelo menos $40 \%$ dos jovens adultos completem o Ensino Superior. Como podemos ver as metas são consideradas ambiciosas, mas os percentuais a serem garantidos são muito pouco expressivos e não resolvem o problema.

6 Sobre competências e a pedagogia das competências, ver: NEVES, Lúcia Maria Wanderley (Org.). A nova pedagogia da hegemonia: estratégias do capital para educar o consenso. São Paulo: Xamã, 2005.

7 Em inglês, são conhecidos pela designação NEET (Not in Employment, Education or Training).

$8 \mathrm{O}$ contrato indefinido é aquele que se faz sem estabelecer um limite de tempo para a prestação dos serviços, e poderá celebrar-se à jornada completa ou parcial. O contrato temporário é aquele que tem definido o tempo para a prestação dos serviços. (Espanha, 2018, disponível em < http://www.empleo.gob.es/es/informacion/contratos/ >, acesso em 4/1/2018, tradução nossa)

9 O PISA - Programa Internacional de Avaliação de Alunos - é uma avaliação internacional estandardizada que mede através da aplicação de provas o conhecimento dos jovens de 15 anos em Leitura, Matemática e Ciências. O exame é realizado pela OCDE (Organização para Cooperação e Desenvolvimento Econômico) e tem por objetivo principal produzir indicadores para comparar o desempenho dos estudantes de diferentes países seguindo os critérios estabelecidos pela própria OCDE no Programa.

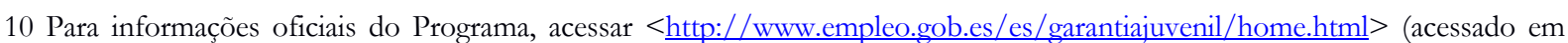
$22 / 01 / 2018)$

11 Esses cursos são oferecidos por diferentes instituições privadas e podem ter duração de 20 dias à 3 meses, com aproximadamente 110h/a, pode ser presencial e/ou online, há cursos com 100\% de subsídios e cursos com valores reduzidos (76 euros, por exemplo) e em seu catálogo de cursos encontra-se, por exemplo: "La Web 2.0 en el aula", "Niños con altas capacidades. Cómo desarrollar su potencial", "TIC indispensables para los docentes", "Enfoque y metodología CLIL en las aulas bilingües", "MEDIACIÓN COMUNITARIA", "Gestión comercial y financiera del transporte por carretera (COML0211)", "Operaciones auxiliares de servicios administrativos y generales (ADGG0408)", "CREACIÓN Y GESTIÓN DE MICROEMPRESAS", "Montaje y mantenimiento de instalaciones frigoríficas", "Microsoft Access 2016 Avanzado", etc. Para ver o catálogo, acessar: $<$ http://www2.lectiva.com/cursos-de-gratuito.htm?gclid=EAIaIQobChMI7--R0t7P2AIVILVRCh1dlATEAEYASAAEgLFJPD BwE> (acessado em 11/01/2018)

12 Ainda que os documentos não especifiquem exatamente quem são os "Interlocutores Sociais", em relação à Estrategia de Emprendimiento y Empleo Joven 2013-2016 indica-se que é fruto de negociações das quais participaram representantes do Ministerio de Empleo y Seguridad Social, da CEOE (Confederación Española de Organizaciones Empresariales), da CEPYME (Confederación Española de la Pequeña y Mediana Empresa), da patronal da CEPES (Confederación Empresarial Española de la Economía Social) e de representações sindicais da UGT (Sindicato Unión General de Trabajadores) e da CCOO (Confederación Sindical de Comisiones Obreras).

13 Documento completo disponível

< http://www.empleo.gob.es/ficheros/garantiajuvenil/documentos/EEEJ Documento.pdf>, acessado em 21/01/2018.

14 Disponível em: <https://loentiendo.com/sistema_nacional_de_garantia_juvenil/>, acesso em jan de 2016.

15 Ver mais em: <http://www.20minutos.es/noticia/2373698/0/informe-juventud/coste-emigracion/consejo-de-lajuventud/\#xtor=AD-15\&xts=467263>, acesso em 16/12/2017.

16 Utilizamos os termos cor e raça, pretos e pardos, juntos ou em separado, por ser assim que aparecem nos documentos do IBGE e em outros abordados. Porém, há um importantíssimo debate acerca da conceituação ao tratarmos das questões étnico-raciais, que não realizamos aqui, por fugir do escopo deste artigo, mas que quisemos registrar por sua importância e pertinência.

Recebido em: 08/05/2019

Aprovado em: 17/06/2019 